\title{
"DEVELOPMENT OF A DAMAGE TOLERANT HEAT TREATMENT FOR CAST + HIP INCOLOY 939"
}

\author{
Robert W. Hatala and John J. Schirra \\ Pratt \& Whitney \\ United Technologies \\ East Hartford, CT
}

\section{Summary}

Current and advanced high thrust and improved efficiency turbine engines require alloys capable of operating at increased temperatures and improved durability. For cast diffuser case applications, additional requirements of weld reparability and castability are also imposed. The cast equiaxed turbine blade alloy Incoloy 939 demonstrated many of these requirements during initial component demonstrations, however preliminary mechanical property characterization showed that material processed with the standard heat treatment exhibited a significant acceleration (and associated intergranular fracture) in $649^{\circ} \mathrm{C}$ hold time crack growth capability. Metallographic evaluation showed the material to exhibit a continuous grain boundary $\mathrm{M}_{23} \mathrm{C}_{6}$ precipitate. A design of experiment approach (Taguchi L8) was utilized to develop a modified heat treatment. Key factors identified were the cooling rate from solution heat treatment, use of a secondary stabilization cycle and slight lowering of the stabilization cycle temperature. Application of the modified heat treatment resulted in suppression of the $649^{\circ} \mathrm{C}$ hold time crack growth acceleration and a transition to a transgranular fracture mode. Metallographic evaluation showed that the modified heat treatment produced a discrete grain boundary $\mathrm{M}_{23} \mathrm{C}_{6}$ precipitate. Additional mechanical property evaluations showed the modified heat treatment resulted in a slight $(<10 \%)$ reduction in room and elevated temperature yield strength and improved ultimate strength and tensile elongation. There was no impact on stress rupture and fatigue (smooth and notch) capability.

\section{Introduction}

Increased thrust and performance demands of advanced turbine engines require materials capable of operating at higher temperatures and or stresses. For example, the current generation of very high thrust commercial engines required diffuser case materials with a $56^{\circ} \mathrm{C}$ to $111^{\circ} \mathrm{C}$ increase in operating capability over the alloy (cast + HIP Inconel 718) used for lower thrust models. Key characteristics of Inconel 718 that make it attractive for diffuser case applications are its relatively good castability and excellent weldability. Two shortcomings observed in the alloy are a propensity to segregate and a tendency to develop surface connected shrinkage porosity that does not heal during the HIP process. Inconel 718 tends to be limited to applications up to $555^{\circ} \mathrm{C}$ to $625^{\circ} \mathrm{C}$.
Alloys considered for increased temperature applications include Mar-M-247, Inconel 713 and Incoloy 939. Wasploy is also a consideration but it does not offer the temperature capability of the previous three. It should be noted that each of the alloys considered for investment cast diffuser case (D/C) applications have all been extensively and successfully used as cast equiaxed turbine airfoils and/or buckets. Applying the weldability criteria of Shira (ref 1), Incoloy 939 appears to be have the best inherent weldablility of the alloys (Figure 1). Research has been conducted (ref 2 to 5) that

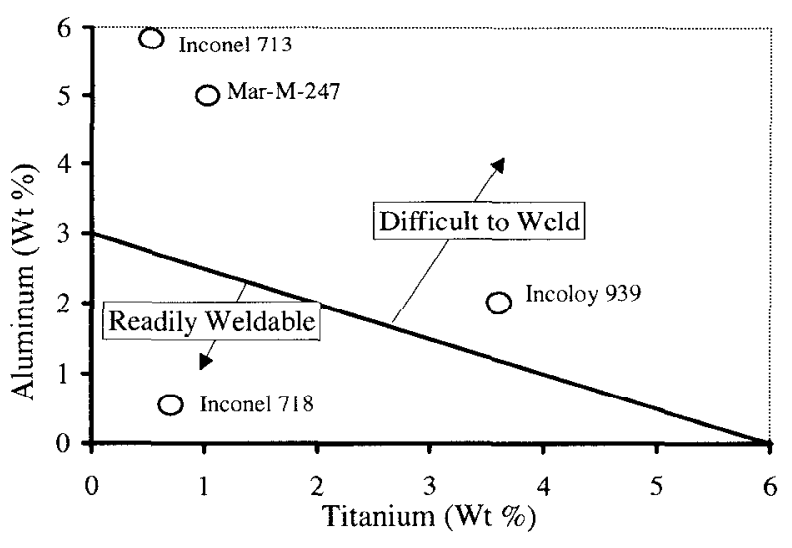

Figure 1

Weldability of Potential and Baseline Investment Cast Structural Case Alloys Based on Shira [1]

suggests Inconel 713 could exhibit adcquate weldability with MarM-247 expected to demonstrate the least weldability. An evaluation conducted by P\&W verifed Incoloy 939 to be the most weldable of the alloys. A significant amount of development activity had also been undertaken by the structural casting industry in identifying the steps required to successfully produce and process investment cast Incoloy 939. Cast test plates were evaluated by P\&W to assess the design capability of the material. The key promising result for the material was the lack of a dwell crack growth acceleration (relative to rapid cycle testing) at $649^{\circ} \mathrm{C}$. Additional mechanical property testing showed adequate capability for diffuser applications. Based on this, additional characterization was conducted. Full scale evaluation of production PW 1000 diffuser cases cast from Incoloy 939 showed the material to exhibit excellent castability and unlike Inconel 718 , tended to develop centerline porosity resulting in an 
enhanced response to HIP. A typical PW 4000 D/C cast from Incoloy 939 is presented in Figure 2, Consistent with preliminary

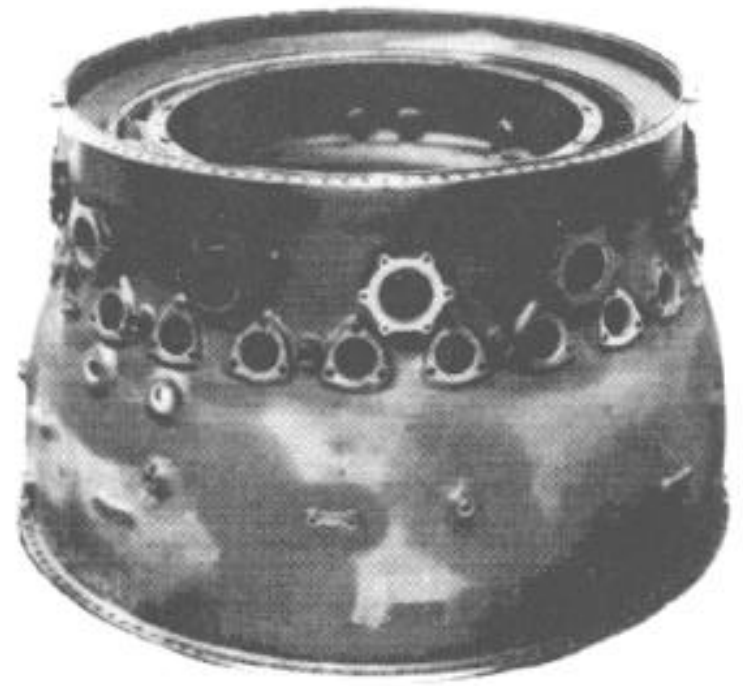

Figure 2

PW 4000 Diffuser Case cast from Incoloy 939

results, weld trials showed the material to exhibit adequate weldability (ref 6,7). The heat treatment selected for the material was that applied to the cast test panels. The cycle consisted of a industry standard three step solution, stabilization \& precipitation

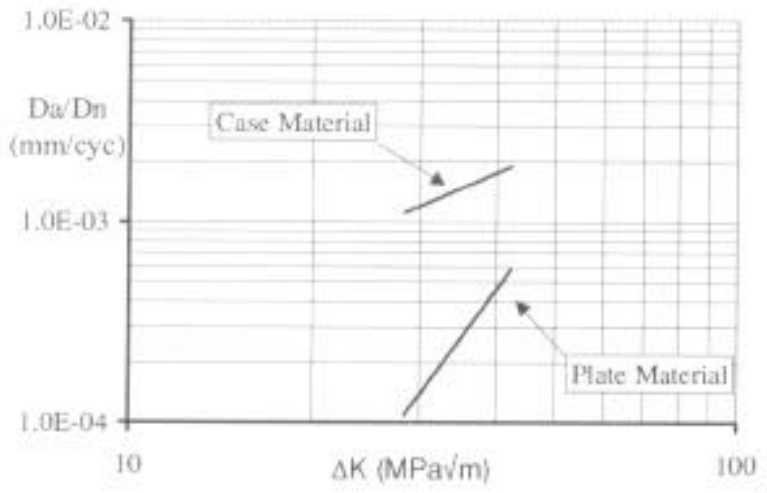

Figure 3

$649^{\circ} \mathrm{C}$ Hold Time Fatigue Crack Growth Rate of Specimens Machined from the Diffuser Case Processed with the Standard Heat Treatment Exhibiled a Significant Accelleration over Specimens Machined from the Plates.

process that was determined to produce the best balance of properties for blade application (ref 8). Evaluation work conducted by the casting industry (ref 9 ) also suggested that the three step heat treat process produced the best balance of monotonic properties.

Hold time (2 minute dwell) crack growth testing at $649^{\circ} \mathrm{C}$ of specimens excised from the casting showed a significant acceleration over the initial cast test panel results (Figure 3 ). This behavior was confirmed by subsequent duplicate tests. Fractography of the tested specimens showed the case material (fast crack growth) to exhibit a predominantly intergranular interdendritic propagation mode with the test panel material showing predominantly transgranular fracture, (Figures 4 \& 5 ). A comparison of the chemistries (Table I)

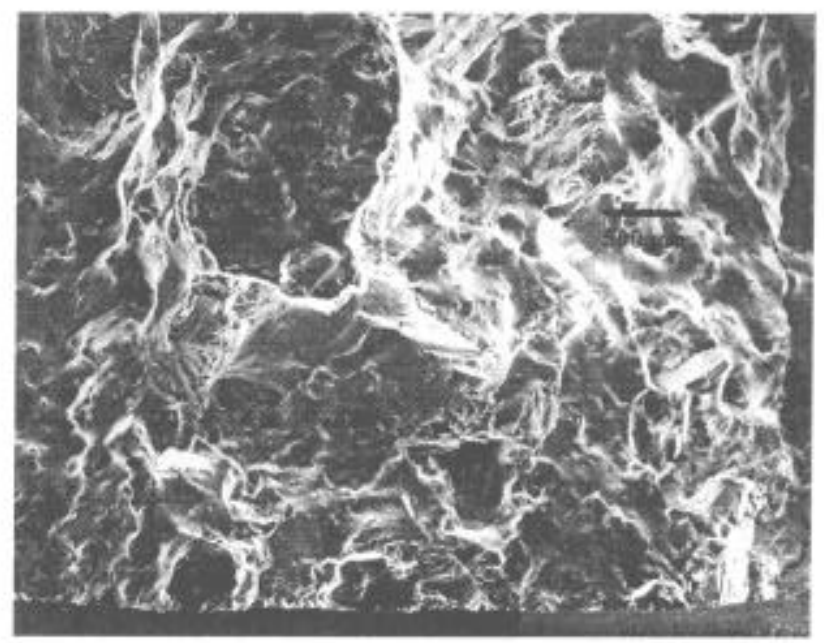

Figure 4

Case Material with Accelerated Crack Growth Rate Exhibited an Intergranular Propogation Mode Under $649^{\circ} \mathrm{C}$, Dwell Conditions

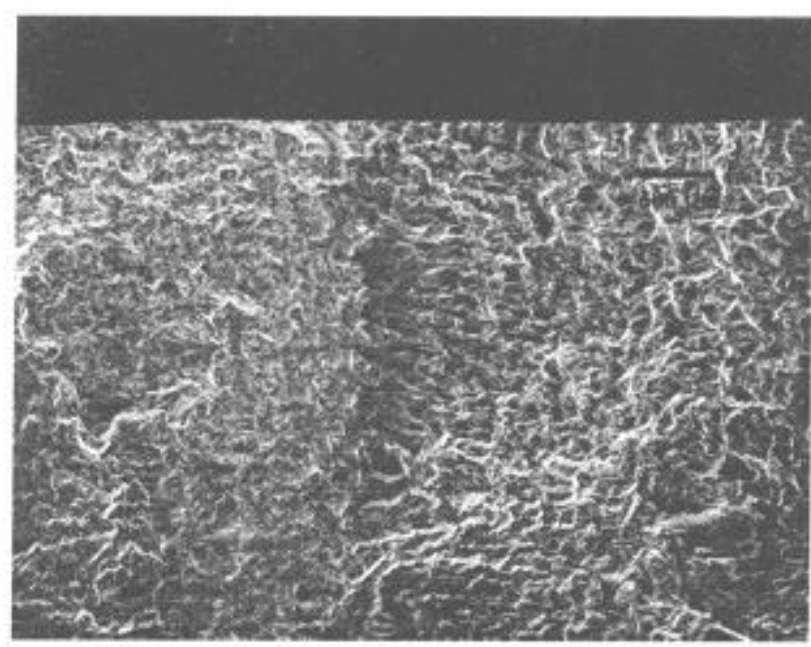

Figure 5

Plate Material with Desirable Crack Growth Rate Exhibited an Transgranular Propogation Mode Under $649^{\circ} \mathrm{C}$, Dwell Conditions

showed no obvious reason for the difference in behavior. Standard metallographic characterization also failed to identify a cause for the accelerated crack growth with both the test panels and case material exhibiting similar microstructural characteristics (Figure 6). Additional characterization of the grain boundary structure 
Table 1

Chemistries (wt \%) of Incoloy 939 Case and Plate Material

\begin{tabular}{|c|c|c|}
\hline Element & Test Panels & Diffuser Case \\
\hline $\mathrm{Cr}$ & 22.7 & 22.7 \\
$\mathrm{Co}$ & 18.6 & 18.6 \\
$\mathrm{~W}$ & 2 & 2 \\
$\mathrm{Al}$ & 2 & 2.1 \\
$\mathrm{Ti}$ & 4 & 3.6 \\
$\mathrm{Ta}$ & 1.4 & 1.3 \\
$\mathrm{Nb}$ & 1 & 1 \\
$\mathrm{C}$ & .13 & .13 \\
$\mathrm{Ni}$ & balance & balance \\
\hline
\end{tabular}

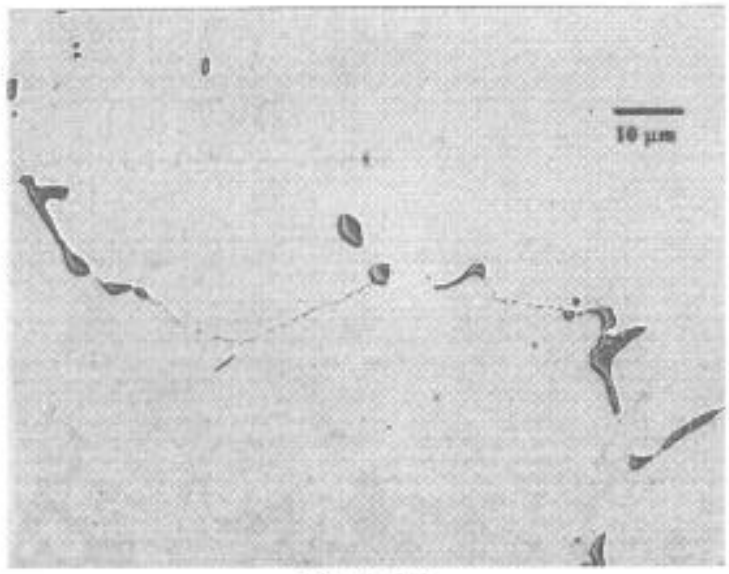

Figure 6-a

Typical Microstructure of Plate Material

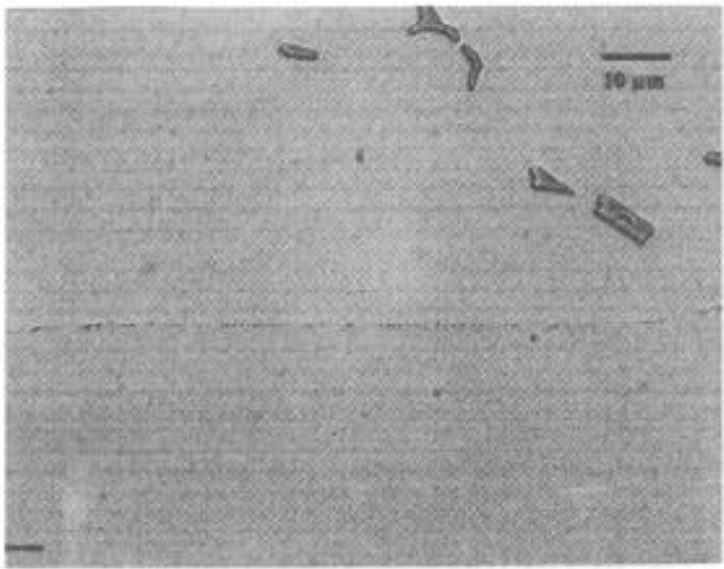

Figure 6-b

Typical Microstructure of Case Material

wus then initiated using a proprietary deep etching technique that has been found useful in investigating grain boundary precipitate networks. The technique consists of an elctropolish followed by an electroetch attacking the $\gamma$ and $\gamma$ phases leaving intermetallic phases in relief. SEM analysis of the deep etch specimens showed the case material to exhibit a continuous grain boundary carbide decoration with the test panel material showing a discrete grain boundary carbide network (Figures $7 \& 8$ ). The hold time crack growth acceleration was attributed to the presence of the grain boundary carbide network.

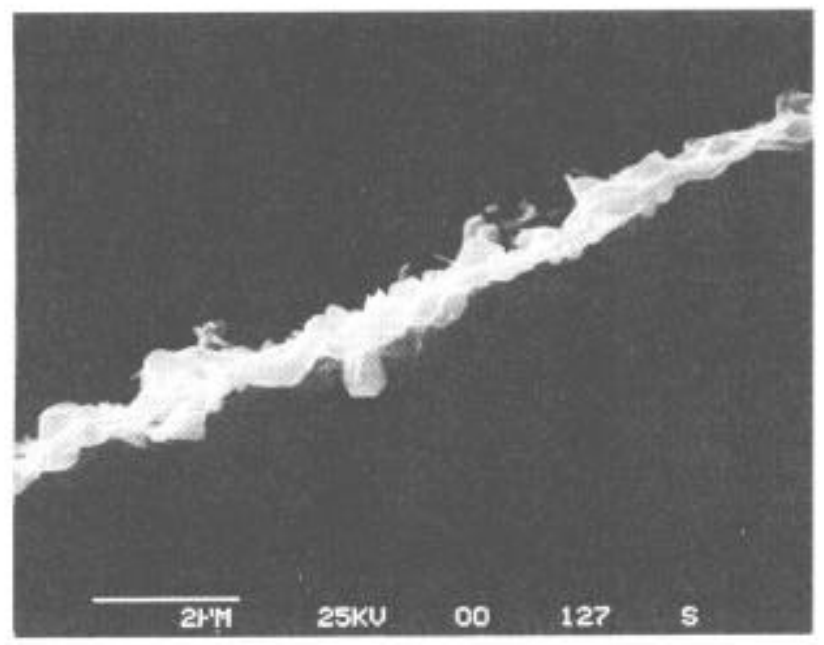

Figure 7

Continuous Grain Boundary Carbide Network Observed in Case Material with Accelerated Crack Growth Rate.

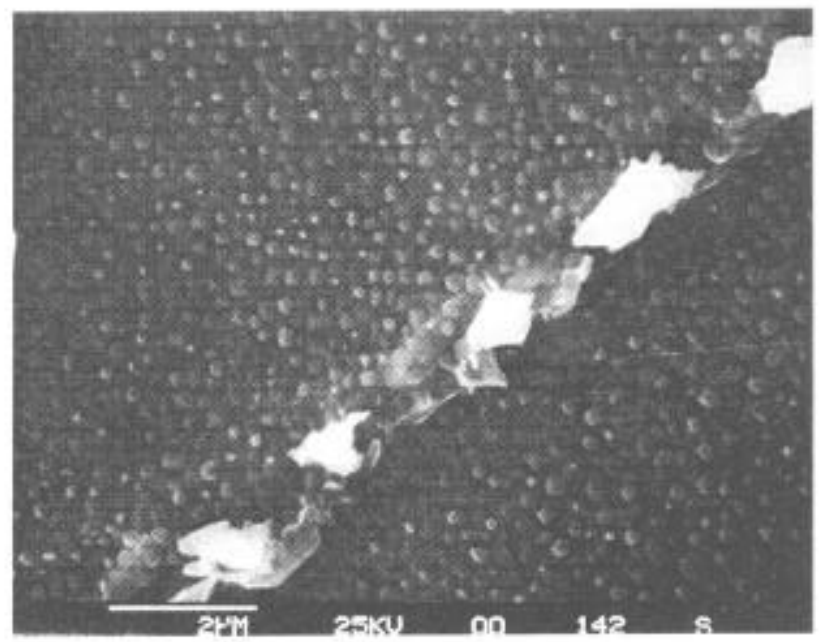

Figure 8

Discrete Grain Boundary Carbide Network Observed in Plate Material with Desirable Crack Growth Rate.

\section{Heat Treatment Development}

The probable cause for the different behavior observed for the case material with respect to the plate material in responding to the standard heat treatment is the effect of casting segregation on the local solvus of the $\mathrm{M}_{23} \mathrm{C}_{6}$ phase. The conjectured origins of the carbide network during the standard heat treatment for the case material includes suppressing the formation of discrete carbides by cooling rapidly from the solution and stabilization cycies (both above or at the $\mathrm{M}_{23} \mathrm{C}_{6}$ solvus) followed by a final age which is low enough to cause enhanced precipitation but too low for significant growth, thus a continuous network is produced. Previous 
experience with high $\mathrm{Cr} /$ high $\mathrm{C}$ alloys such as Waspaloy \& IN100 suggested that the continuous grain boundary carbide network could be modified through heat treatment. Modifications that could be applied included using a controlled, slow cool from the solution heat treatment to produce carbide nuclei (and provide an additional benefit in serrating the grain boundary); applying an intermediate stabilization cycle after cooling from the solution heat treatment to grow the carbide nuclei into discrete particles; lower the stabilization temperature to ensure that the $\mathrm{M}_{23} \mathrm{C}_{6}$ solvus is not exceeded and increase the age temperature to decrease the propensity to form a carbide film. To establish the individual and interactive effects of these various heat treatment options on modifying the grain boundary carbide structure, a design of experiments approach was utilized. The matrix (based upon Taguchi methods) selected was a L8 (ref 10) to assess the effect of the four heat treatment modifications discussed above. The variables selected and the experimental levels used are listed in Table 2 together with the paraneters for individual experinental runs. The material used for the experiment was sectioned from the fully heat treated case that exhibited the continuous grain boundary carbide. Upon completion of the heat treatment the samples were subjected to standard metallographic preparation procedures and evaluated. There was very little difference in the microstructure observed optically. However, when the samples were subjected to a deep etch / SEM evaluation it became evident that there were significant differences in the structure and distribution for the grain boundary carbide. Typical carbide structures varied from discrete particles to semi-continuous and continuous networks and they are presented in Figure 9. To provide a semiquantitative approach to analyzing the results, a grain boundary film factor was applied to each of the structures and used as the response variable. In addition, measurements were made using the photomicrographs to estimate interparticle spacing of the carbides and additional assessments of the grain boundary "filmines" solicited. A summary of the results is presented in Table III.

Table III

Heat treat development matrix results and rating of grain boundary carbide structure

\begin{tabular}{|c|c|c|c|}
\hline Run \# & Film Factor $^{1}$ & Film Factor $^{2}$ & ${\text { Carbide Spacing }(\mu \mathrm{m})^{3}}^{3}$ \\
\hline 1 & 10 & 10 & 2.42 \\
2 & 10 & 10 & 4.02 \\
3 & 10 & 4 & 5.26 \\
4 & 10 & 8 & 3.00 \\
5 & 5 & 3 & 0.06 \\
6 & 3 & 1 & 1.87 \\
7 & 2 & 2 & 1.50 \\
8 & 10 & 6 & 2.81 \\
\hline
\end{tabular}

1) Assessment by evaluator \#1.

2) Assessment by evaluator \#2.

$$
\begin{gathered}
10=\text { no film } \\
0=\text { film }
\end{gathered}
$$

3) Distance between adjacent particles.

Table II

Heat treatment development matrix showing experimental variables and levels

\begin{tabular}{|c|c|c|c|c|}
\hline Run \# & Cooling Rate & Intermediate Stabilization Cycle & Stabilization Cycle & Age Cycle \\
\hline 1 & $111-167^{\circ} \mathrm{C} / \mathrm{hr}$ & none & $954^{\circ} \mathrm{C} / 6 \mathrm{hrs}$ & $802^{\circ} \mathrm{C} / 4 \mathrm{hrs}$ \\
2 & $111-167^{\circ} \mathrm{C} / \mathrm{hr}$ & $913^{\circ} \mathrm{C} / 8 \mathrm{hrs}$ & $954^{\circ} \mathrm{C} / 6 \mathrm{hrs}$ & $843^{\circ} \mathrm{C} / 4 \mathrm{hrs}$ \\
3 & $111-167^{\circ} \mathrm{C} / \mathrm{hr}$ & $913^{\circ} \mathrm{C} / 8 \mathrm{hrs}$ & $999^{\circ} \mathrm{C} / 6 \mathrm{hrs}$ & $802^{\circ} \mathrm{C} / 4 \mathrm{hrs}$ \\
4 & $111-167^{\circ} \mathrm{C} / \mathrm{hr}$ & none & $999^{\circ} \mathrm{C} / 6 \mathrm{hrs}$ & $843^{\circ} \mathrm{C} / 4 \mathrm{hrs}$ \\
5 & $>1000^{\circ} \mathrm{C} / \mathrm{hr}$ & $913^{\circ} \mathrm{C} / 8 \mathrm{hrs}$ & $954^{\circ} \mathrm{C} / 6 \mathrm{hrs}$ & $843^{\circ} \mathrm{C} / 4 \mathrm{hrs}$ \\
6 & $>1000^{\circ} \mathrm{C} / \mathrm{hr}$ & none & $954^{\circ} \mathrm{C} / 6 \mathrm{hrs}$ & $802^{\circ} \mathrm{C} / 4 \mathrm{hrs}$ \\
7 & $>1000^{\circ} \mathrm{C} / \mathrm{hr}$ & none & $999^{\circ} \mathrm{C} / 6 \mathrm{hrs}$ & $843^{\circ} \mathrm{C} / 4 \mathrm{hrs}$ \\
8 & $>1000^{\circ} \mathrm{C} / \mathrm{hr}$ & $913^{\circ} \mathrm{C} / 8 \mathrm{hrs}$ & $999^{\circ} \mathrm{C} / 6 \mathrm{hrs}$ & $802^{\circ} \mathrm{C} / 4 \mathrm{hrs}$ \\
\hline
\end{tabular}

1) Cooling rate from $1163^{\circ} \mathrm{C} / 4$ hours solution heat treat cycle.

Heat treat procedure : Solution $(\& \mathrm{cool})+$ intermediate stabilization + stabilization + age. 


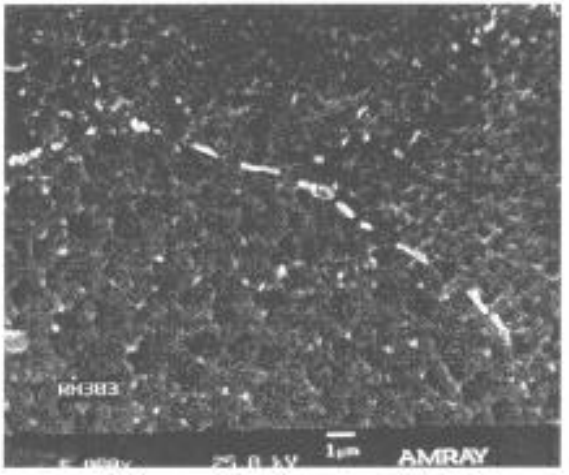

Run \#1

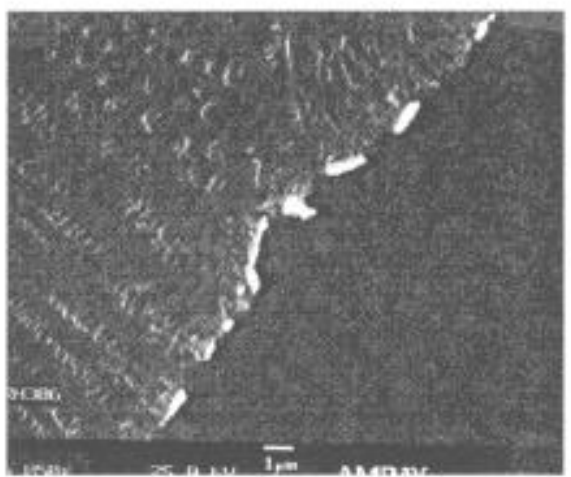

Run \#4

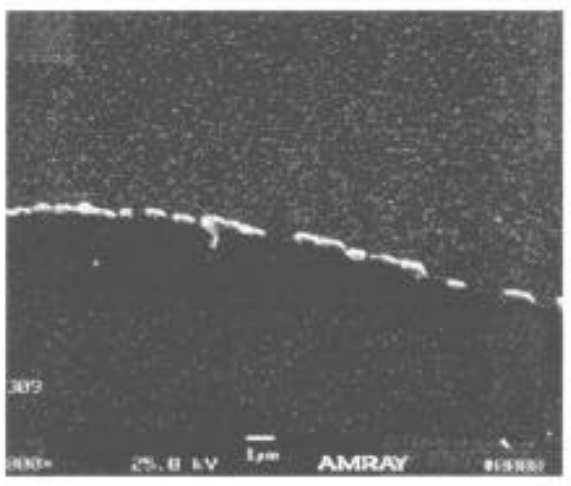

Run \#7

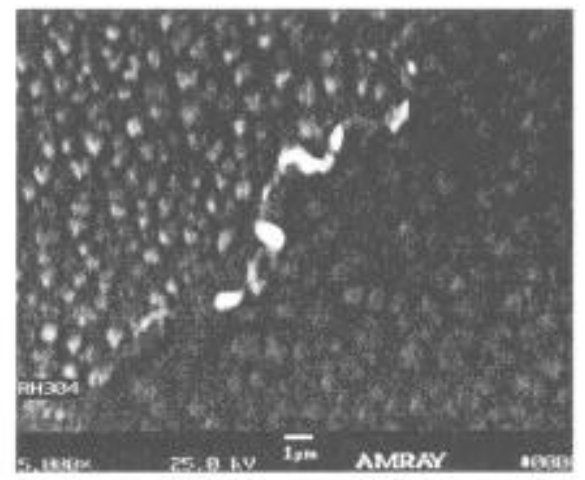

Run $\# 2$

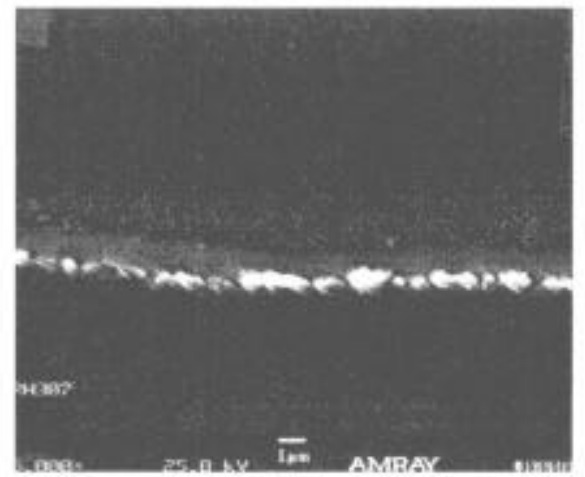

Run 45

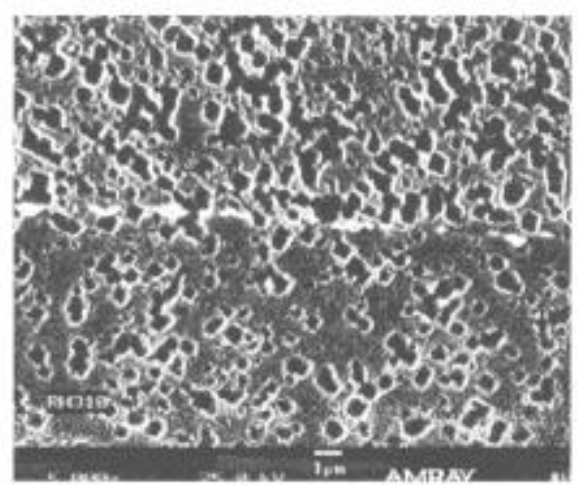

Run $\# 8$

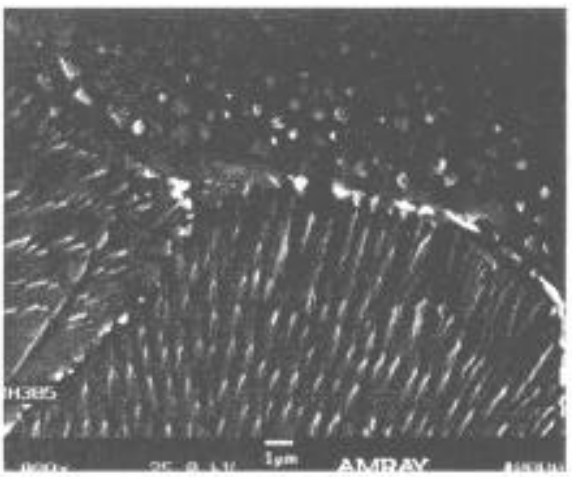

Run \#3

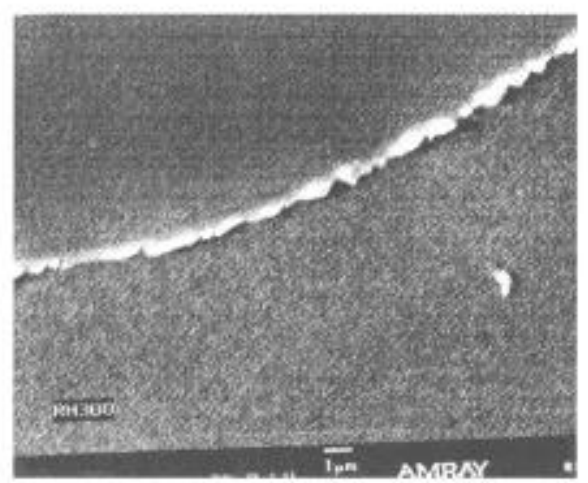

Run \#6

Figure 9

Grain Boundary Carbide Structures Observed in lncoloy 939 Processed Through the Experimental Heat Treatments Listed in Table II

Analysis showed that of the factors evaluated, slower cooling rate from solution heat treatment and use of an intermediate stabilization heat treatment resulted in the formation of a discrete grain boundary carbide structure. To verify the trends observed in the experiment, two confirmation heat treatments and a baseline heat treatment were conducted. The heat treatments are listed in Table IV Confirmation heat treatment " $Y$ " resulted in a discrete grain boundary carbide structure (Figure 10) with confirmation heat treatment " $\mathrm{X}$ " also producing an attractive grain boundary structure (Figure 11). The baseline heat treatment resulted in a 
Table IV

Comparison of Standard and Modified Heat Treatments for Incoloy 939

\begin{tabular}{|c|c|c|c|}
\cline { 2 - 4 } \multicolumn{1}{c|}{ Cycle } & Standard & "X" & ${ }^{\circ} \mathrm{Y} "$ \\
\hline Solution HT & $1163^{\circ} \mathrm{C} / 4 \mathrm{hrs}$ & $1163^{\circ} \mathrm{C} / 4 \mathrm{hrs}$ & $1163^{\circ} \mathrm{C} / 4 \mathrm{hrs}$ \\
Cool from Solution & $>1000^{\circ} \mathrm{C} / \mathrm{hr}$ & $139^{\circ} \mathrm{C} / \mathrm{hr}$ & $139^{\circ} \mathrm{C} / \mathrm{hr}$ \\
Intermediate & & & \\
Stabilization Cycle & none & none & $912^{\circ} \mathrm{C} / 6 \mathrm{hrs}$ \\
Stabilization Cycle & $999^{\circ} \mathrm{C} / 4$ hrs & $968^{\circ} \mathrm{C} / 4 \mathrm{hrs}$ & $982^{\circ} \mathrm{C} / 4$ hrs \\
Age Cycle & $802^{\circ} \mathrm{C} / 4$ hrs & $802^{\circ} \mathrm{C} / 4 \mathrm{hrs}$ & $802^{\circ} \mathrm{C} / 4$ hrs \\
\hline
\end{tabular}

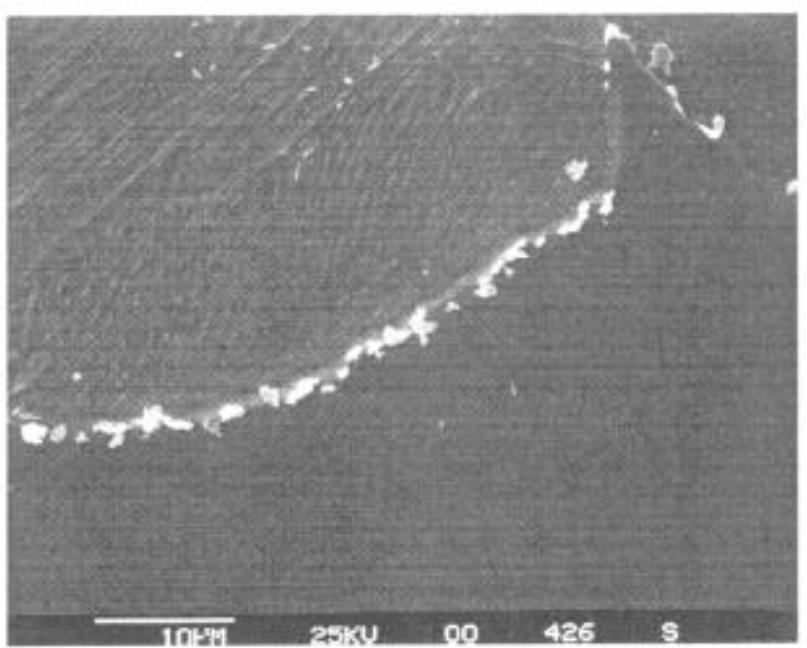

Figure 10

Modified Heat Treatment ' $\mathrm{Y}$ " Produced Discrete Grain Boundary Carbide Network

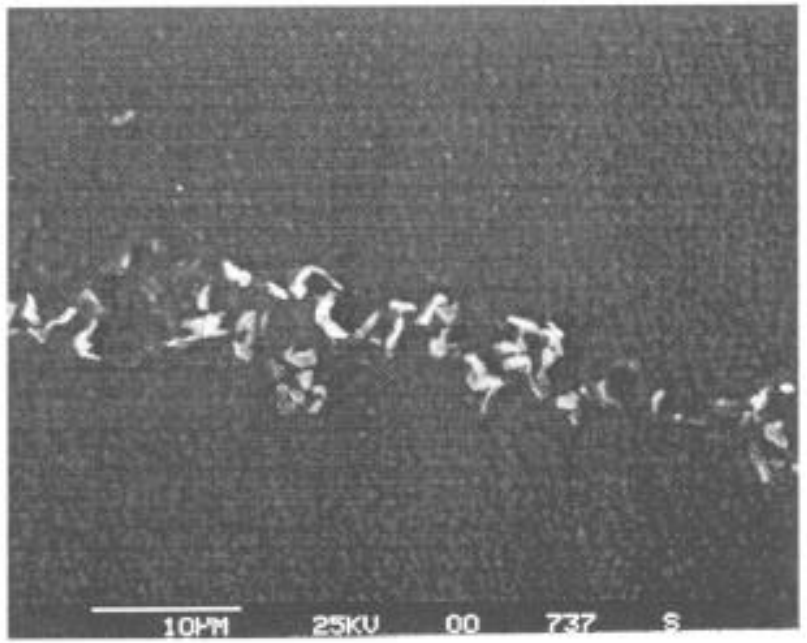

Figure 11

Modified Heat Treatment ' $\mathrm{X}$ " Produced Discrete Grain Boundary Carbide Network

continuous grain boundary carbide film. To determine if hold time crack growth properties were affected, additional case material was processed through the two confirmation heat treatments for specimen testing. Crack growth testing under hold time conditions at $649^{\circ} \mathrm{C}$ showed that both heat treatment " $\mathrm{X}$ " and heat treatment " $\mathrm{Y}$ " resulted in improved crack growth resistance compared to the baseline material. A comparison is presented in Figure 12. Post test specimen analysis showed that both modified heat treatments resulted in a transition to transgranular fracture from the intergranular / interdendritic fracture mode observed for the standard heat treatment. Because of the greater improvement in crack growth propertics, heat treatment " $\mathrm{Y}$ " was selected for evaluation of additional specimens from multiple heats of material. All specimens tested continued to show improved hold time crack growth resistance, P\&W's material specification was changed to reflect the modified heat treatment and patent protection (patent pending) solicited for the heat treatment. A comparison between the standard and modified heat treatments is presented in Table IV.

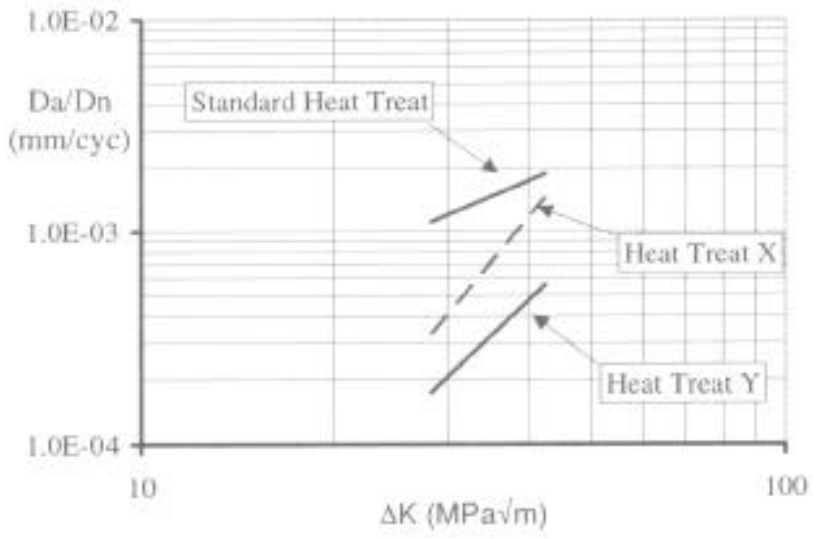

Figure 12

Modified Heat Treatments Improve the $649^{\circ} \mathrm{C}$ Hold Time Fatigue Crack Growth Rate of Incoloy 939

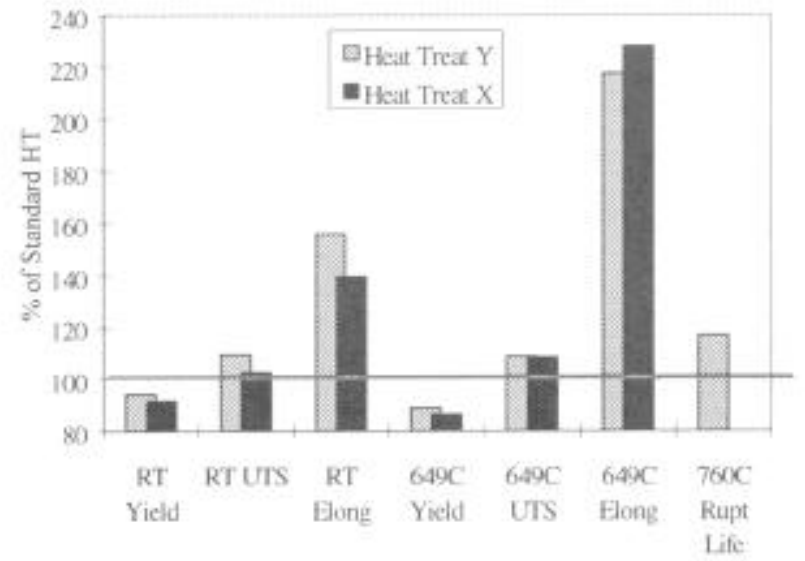

Figure 14

Modifed Heat Treatments Result in Improved Balance of Properties for Incoloy 939 Relative to Material Processed with the Standard Heat Treatment. Stress Rupture Testing of HT "X" was not Conducted.

The heat treatment modifications would be expected to, and did, alter the size and distribution of the $\gamma^{\prime}$ phase. A coarser secondary 
$\gamma$ ' developed due to the controlled cool from the solution heat treatment and there was a reduced volume fraction cooling $\gamma^{\prime}$ due to the lowering of the second stabilization cycle temperature. To address this, additional mechanical property characterization of the modified heat treatment has been conducted and the results indicate that an attractive balance of properties is attained. In general, the modified heat treatment results in a slight or no reduction in capability relative to the standard heat treatment. A comparison is presented in Figure 13. With respect to cast Inconel 718, Incoloy 939 with the modified heat treatment offers the potential for a $111^{\circ} \mathrm{C}$ improvement in operating temperature and a $56^{\circ} \mathrm{C}$ increase over cast Waspaloy.

\section{Acknowledgments}

Several people at Pratt \& Whitney's Materials \& Mechanics Engineering Organization contributed to the development of the modified heat treatment. Key contributors inciude Tony Cabral who conducted fractography of tested specimens, Tom Kenney who assisted in material processing and metallographic characterization and Klaus Gumz, Greg Levan and Al Nytch who provided deep etch / SEM analysis and documentation.

\section{$\underline{\text { References }}$}

1. M. Prager and C. S. Shira, "Weldability of $\gamma$ ' Strengthened Alloys", Welding Research Council Bulletin \#128, 1968

2. H. Ikawa, S. Shin, \& Y. Nakao; "Weldability of Nickel-Base Heat Resisting Superalloy - Effect of Aluminum Content on the Weld Crackings in Inconel 713C - ";Osaka University Technology Reports; vol 18 (1968); 353-361

3. H. Ikawa, S. Shin, \& Y. Nakao; "Weldability of Nickel-Base Heat Resisting Superalloy - Main Cause of Weld Crackings in Heat Affected Zone of Inconel 713C - ";Osaka University Technology Reports; vol 21 (1971); 101-120

4. H. Ikawa, S. Shin, \& Y. Nakao; "Weldability of Nickel-Base Heat Resisting Superalloy - Improvement of Hot Cracking Sensitivity of Inconcl $713 \mathrm{C}$ and Its Mcchanical Properties "; Osaka University Technology Reports; vol 21 (1971); 461-474

5. A. Koren, et. al.; "The Effect of Weld Energy Input Parameters on the Crack Sensitivity of Alloy IN 713 C"; Welding Research Supplement ;November 1982; 137-149

6. J. Peng; "Weld Results of P\&W Inco 939 B-Pads", Precision Castparts Corporation Internal Report, 11/29/89

7. J. Peng; "Weld Evaluation of Inco 939 Diffuser Case", Precision Castparts Corporation Internal Report, 5/21/91

8. S. Shaw, K. Delargy, G. Smith; "Effects of Heat Treatment on Mechanical Properties of High -Chromium Nickel-Base Superalloy IN 939"; Materials Science and Technology; October 1986; 10311036
9. J. Snow, O. Ballou; "Inco 939 Alloy Investigation - Final Report"; Precision Castparts Corporation Internal Report; October 1988

10. G. Taguchi; Introduction to Quality Engineering; American Supplier Institute - Dearborn, MI; 1986; pg 182 